\title{
MELHOR PARA QUUEM: o Juizado de Órfãos e o discurso de valorização e proteção aos menores de idade no início do século XX
}

\author{
José Carlos da Silva Cardozo*
}

\section{Resumo}

Nos anos iniciais do século XX, havia o discurso social de valorização e proteção aos menores de idade. Nesse período, muitos adultos requereram a tutela de crianças com o objetivo de zelar pela saúde, alimentação, moradia e educação dessas. A tutela era um encargo requerido por uma pessoa ao Juízo dos Órfãos para que esta gerenciasse os bens e cuidasse da integridade física do menor. Porém, se havia todo um discurso de bem-estar dos menores, por que os adultos optavam pela tutela ao invés da adoção? Este estudo procura problematizar e supor algumas respostas para essa indagação.

Palavras-chave: Tutela. Adoção. Menor de Idade.

\section{Introdução}

Os anos iniciais do século XX foram anos em que a sociedade brasileira, assim como a mundial, estava em completo estado de euforia promovido pela ciência, ideia de modernidade e progresso, que o novo século estava a ofertar. Mas, para usufruir de toda a "prosperidade" que o novo tempo estava a trazer era necessário mudar hábitos e costumes da população, principalmente daqueles de origem popular.

A nova sociedade desejada não deveria reproduzir os antigos costumes da sociedade monárquica que administrara o Brasil por longos anos, assim, no centro de toda essa organização da sociedade estava a família e, principalmente, seu pequeno integrante, a

\footnotetext{
*Historiador (UNISINOS), Cientista Social (UFRGS) e Doutorando em História Latino-Americana pela Universidade do Vale do Rio dos Sinos - UNISINOS, instituição Jesuíta de ensino localizada na cidade de São Leopoldo - Rio Grande do Sul. Bolsista Capes/MEC. E-mail: jcs.cardozo@gmail.com
} 
criança. Regrando o núcleo fundamental de qualquer sociedade se estaria regrando a sociedade por completo. Dessa forma, com a atenção direcionada para a estrutura familiar, as elites buscavam reorganizar os hábitos e os costumes da população porto-alegrense, e uma das instituições que contribuiu para que isso ocorresse foi o Juizado Distrital da Vara de Órfãos de Porto Alegre, ou simplesmente, Juízo dos Órfãos ${ }^{1}$, que direcionou suas atenções para os menores que passavam por algum tipo de desestruturação familiar e necessitavam de um amparo legal para suas necessidades.

O Juízo de Órfãos é uma instituição que teve sua origem em Portugal, remontando às Ordenações Filipinas que formaram o código jurídico a partir de 1580. Até o século XVIII, esse cargo era exercido pelo Juiz Ordinário, que não tinha formação em Direito. Com o crescimento da população colonial, em maio de 1731, foi regulamentado o cargo de Juiz de Órfão no Brasil e, a partir dessa data, as questões relacionadas aos menores passaram a ser de sua responsabilidade (RODRIGUEZ, 2010).

Então, o Juizado de Órfãos foi, desde o período Colonial até o início da República, uma das instituições mais importantes para a regularização das questões relativas à família e à criança, desempenhando, ao longo do tempo, atividades de proteção ao menor. Conforme Gislane Azevedo (1995) essa instituição cuidava, num primeiro momento, dos menores da elite, na resolução de questões envolvendo suas heranças, da relação entre os menores e seus familiares ou tutores, como também de outras que diziam respeito à sua renda e a seus bens para, depois, com a formação de novas relações sociais, como as decorrentes do surgimento da figura do ingênuo, passar a direcionar atenção especial para o cuidado (abandono, saúde, moradia, roupas e educação) da criança pobre. Isso passou a ocorrer porque as instituições públicas tornaram esses indivíduos às figuras centrais no espaço familiar (PAPALI, 2003; LEWKOWICZ, 2008).

O Juizado de Órfãos, ao longo do tempo, transformou-se em um órgão essencial para o encaminhamento de questões quanto à desagregação familiar envolvendo crianças. Preocupado com o universo infantil, o Juízo dos Órfãos mediou ações praticadas pela família, pois essa era considerada o espaço gestor dos padrões e regras de comportamento social, assim, o Estado estava preocupando-se em influenciar o privado da família.

\footnotetext{
${ }^{1} \mathrm{O}$ termo órfão não deve ser entendido estritamente, pois pode representar menores órfãos de pai e mãe como
} também os “órfãos de pais vivos”, ou seja, representava igualmente aqueles que tinham seus progenitores vivos. 
A primeira pesquisa de que temos conhecimento, que apresenta uma abordagem sobre processos desse órgão jurídico no Rio Grande do Sul, foi da antropóloga Cláudia Fonseca² (2006), que buscou discutir a circulação das crianças no início do século XX. Nesse estudo, originalmente publicado em 1989, Fonseca investigou 149 processos de “Apreensão de Menores”, essa autora procurou demonstrar que a prática, hoje tão comum nas famílias populares, de um terceiro (parente sanguíneo ou não) cuidar de um menor já era usual no início do século XX.

Estudos posteriores, em outras localidades, utilizaram outra fonte judicial igualmente produzida no âmbito do Juízo dos Órfãos - os processos de tutela. Estas pesquisas detiveramse nas mudanças de caráter econômico promovidas pela Lei do Ventre Livre, de 1871, até a Abolição da Escravidão, em 1888; os trabalhos apresentam as estratégias empregadas pelos senhores de escravos na manutenção dos serviços, tanto os praticados no âmbito público, quanto àqueles realizados no âmbito doméstico, mediante a tutela dos filhos das escravas 3 . Nossa dissertação de mestrado intitulada Enredos tutelares (CARDOZO, 2011) analisou a tutela na cidade de Porto Alegre em período posterior, os anos iniciais do século XX, e verificou que os valores sociais e morais estavam mudando, tanto por conta das transformações modernizadoras que a sociedade passava quanto das imposições reguladoras do convívio social que o novo regime político-administrativo requeria, e assim, influenciando

\footnotetext{
${ }^{2}$ A primeira edição de seu livro foi publicada em 1995, porém o estudo utilizando essa documentação já havia sido publicado, com poucas alterações no ano 1989. Embora o trabalho de Cláudia Fonseca tenha que ser valorizado pelo uso pioneiro dessa fonte no Rio Grande do Sul, ela não apresenta a localização dos processos por ela pesquisados. Contudo, isso não compromete seu estudo, aliás, é de ser enaltecida a capacidade investigativa da autora que não se limitou a pesquisar em local pouco frequentado por antropólogos, como um arquivo histórico.

${ }^{3}$ Como exemplos de pesquisas que exploraram os processos judiciais de tutela podemos apresentar o estudo de Gislane Campos Azevedo (1995), em que a autora, embora afirme que seu objetivo tenha sido o de refletir sobre os significados sociais da ação dos Juízes de Órfãos, Ausentes e Anexos da Capital (São Paulo) durante os anos de 1871 a 1917, essa não conseguiu se desvencilhar do problema exposto pela Lei do Ventre Livre (como a própria delimitação inicial apresenta), tangenciando pequenas incursões sobre o início do século XX até a entrada em vigor do Código Civil Brasileiro (1917). Anna Gicelle Alaniz (1997) apresenta um estudo mais rico pelas várias fontes documentais de que utilizou, como registros paroquiais (assentos de óbito), atas da Câmara Municipal e, sobretudo, os processos judiciais de Tutela, Apreensão de Menores, Licenças para Casamento e Remoção de Tutela da cidade de Campinas e Itu (São Paulo), no período de 1871 a 1885; nesse estudo, ela procurou verificar as estratégias de sobrevivência das famílias escravas, negras e libertas (forras) diante da legislação abolicionista. Já Maria Aparecida C. R. Papali (2003) buscou identificar os trâmites emancipacionistas, as tensões abolicionistas e a disputa pela mão de obra dos libertos e dos órfãos (ingênuos) na cidade de Taubaté (São Paulo) entre os anos de 1871 a 1895. Luciana de Araujo Pinheiro (2003) estudou a criança pobre a partir dos relatórios dos Chefes de Polícia da Corte, dos Ministros da Justiça, dos Presidentes da província do Rio de Janeiro e do Juizado de Órfãos da capital do Brasil e investigou aqueles juízes que assumiram a cadeira na $2^{\text {a }}$ Vara de Órfãos e Ausentes, valendo-se, para isso, dos processos de tutela, sendo que também seu período de análise se concentrou entre os anos de 1879 e 1889. Arethuza Helena Zero (2004) pesquisou as ambiguidades da Lei do Ventre Livre, procurando entender as formas de controle social exercidas sobre as crianças, no período de 1871 até 1888, focando, principalmente, sua análise na exploração do trabalho infantil.
} 
tanto aqueles que pleiteavam a tutela de um menor quanto os juristas que avaliavam a solicitação.

A tutela era dividida em 3 tipos, conforme as Ordenações Filipinas (liv. $4^{\circ}$, tit. 102, §1, 5 e 7) em:

$$
\begin{aligned}
& 1^{\circ} \text { - Testamentária, } \\
& 2^{\circ} \text { - Legítima } \\
& 3^{\circ} \text { - Dativa. }
\end{aligned}
$$

O primeiro tipo referia-se àquelas tutelas determinadas em testamento, quando o pai deixava explicitamente nomeada a pessoa que seria a tutora do(s) filho(s); geralmente, isso era feito pelas famílias que possuíam bens. O segundo tipo de tutela incluía aquelas em que a lei nomeava o tutor, por conta da falta ou incapacidade do testamentário, que era indicado/escolhido entre os parentes consanguíneos do menor. O último tipo era a tutela em que, na falta do primeiro e segundo casos, o próprio Juízo de Órfãos nomeava uma pessoa sem laços sanguíneos com o menor para o cargo de tutor, que, por ser dativo, somente era obrigado a exercer a função por até dois anos (Ord. Fil. liv. 4º, tit. 102 §9). Assim, em vista da lei, seguia-se essa classificação para atribuir uma tutela. Quando a pessoa era nomeada, não era possível a recusa ao cargo, salvo por motivo justo, como doença.

A mãe da criança ou adolescente, segundo a legislação, estava em linha tênue perante a Justiça, pois perderiam o direito da tutela aquelas que realizassem segundas núpcias, mesmo sendo viúvas, ou que deixassem de viver "honestamente”. Nesses casos, essas mulheres não poderiam reaver a tutela ainda que enviuvassem novamente (Ord. Fil. liv. 4º tit. 102 §4). Já as avós viúvas tinham a preferência, desde que renunciassem ao Velleano ${ }^{4}$ e igualmente vivessem "honestamente” e não recasassem; depois, os outros parentes consanguíneos do menor, não sendo, porém, aceitos aqueles que se oferecessem para o cargo (Ord. Fil. liv. 4º, tit. $102 \S 3$ e 5).

Em Porto Alegre, capital do Rio Grande do Sul, já havia Juiz de Órfãos, desde 1806, criado pela Real Resolução, transpôs o período Imperial chegando até a República, quando

\footnotetext{
${ }^{4}$ A Lei do Velleano era um benefício dado às mulheres em que elas não poderiam ser fiadoras e nem obrigadas por outros a serem. A renúncia era fundamental, pois, se o menor possuísse bens, a avó deveria, como todo o tutor de menor, realizar depósito no Cofre dos Órfãos como forma de garantia; caso utilizasse de forma imprópria os bens ou rendimentos do menor, este estaria com uma reserva no Cofre dos Órfãos quando atingisse a maioridade; ou, mesmo que o menor não possuísse bens, ela deveria estar apta a ser em razão de alguma necessidade do menor.
} 
houve a criação em 1927 e a substituição em definitivo deste Juízo pelo Juizado de Menores ${ }^{5}$, em 1933.

Neste sentido, podemos depreender da documentação processual e regulatória do Juízo dos Órfãos que, cuidar das crianças e adolescentes era um dos principais objetivos da sociedade e do Estado que por meio de suas instituições procurara zelar pela saúde, alimentação, educação e moradia para as crianças. Quando uma criança estava a enfrentar alguma situação de risco proporcionada pela ausência de seus pais ou responsáveis, o Juizado de Órfãos agia com vista a promover o bem-estar do menor, atribuindo-lhe um novo responsável que tivesse obrigações legais para com esse pequeno integrante da sociedade.

Esse foi o objetivo de Manoel Escobar quando ficou sabendo o que ocorrera com a pequena Eulina.

"Papai"

As vidas das famílias Escobar e Barcellos Pinheiro não seriam mais as mesmas depois daquele encontro na agência de criados, da Rua Barros Cassal, em 1918. Duas pessoas haviam se cruzado naquele local, e, como consequência desse encontro, muitas vidas seriam transformadas e uma batalha judicial seria travada.

O Desembargador aposentado Manoel Ferreira Escobar Júnior foi até aquele estabelecimento com a finalidade de encontrar uma pessoa que pudesse limpar sua casa, uma doméstica. Chegando lá, foi apresentado à Julieta Barcellos Pinheiro, mulher de cor branca, com 27 anos de idade e mãe solteira. Segurando uma menininha nos braços, contou de sua necessidade de trabalhar, pois fora expulsa de casa pelos pais por ter sido iludida e deflorada pelo seu antigo noivo e, como se não bastasse a vergonha por que passara, havia engravidado. Sendo assim, tinha que trabalhar para sustentar a si e a filha, que acabara de nascer havia apenas 2 meses.

A história de Julieta Pinheiros sensibilizou o Desembargador que, mesmo casado havia muitos anos, não conseguia ter filhos. Assim, Manoel contratou-a como criada, levando ela e a menina Eulina ${ }^{6}$ para morar em sua casa.

\footnotetext{
${ }^{5}$ Sobre o Juizado de Menores em Porto Alegre, ver o artigo de ZANELLA, Ana Paula. A administração do Juizado de Menores do Rio Grande do Sul nos seus primórdios (1933 a 1945). Revista Justiça \& História. Tribunal de Justiça do Estado do Rio Grande do Sul, Porto Alegre, v. 3, n. 5, p. 225-243, 2003.

${ }^{6}$ RIO GRANDE DO SUL. Juízo Districtal da Vara de Orphãos de Porto Alegre. $3^{\text {a }}$ Vara. Tutela. Proc. $n^{\circ} 780$ de 1924. [manuscrito]. Porto Alegre, 1924. Localização: APERS. Esclarecemos que os excertos extraídos dos processos se encontram entre aspas e em itálico, sendo que o número da página da qual foram extraídos será informada em nota de rodapé apenas quando a mesma tiver sido esgotada em termos de análise.
} 
Tudo corria bem entre a mãe da menina e seus patrões, mas, "em novembro do ano passado [1923], a mãe da menor pediu-a para, em visita, leva-la à casa dos avós”, e não voltou mais, nem ela, nem a criança. Não havia motivo aparente para isso, mas talvez os avós tivessem reconsiderado sua posição anterior e acolhido mãe e filha.

A família Escobar ficou entristecida com as ausências, principalmente da menina, por quem tinham muito carinho e afeto. O Desembargador chegou a cogitar em retirar a menina da mãe, mas “embora soubesse da pobreza da mãe para educar a filha”, deixou Eulina "ficar em poder dela",.

Contudo, os eventos que se sucederam após a visita de Eulina e sua mãe à casa dos avós, em novembro de 1923, culminando com o falecimento de Julieta, às 14 horas do dia 5 de junho de 1924, por tuberculose, na Rua do Caminho do Meio, alterariam os dias das famílias Escobar e Barcellos Pinheiro - pois agora havia uma criança, órfã de mãe, a ser cuidada.

A notícia da morte de Julieta foi o estopim para Manoel Escobar pedir a guarda de Eulina. Procurou a menina na casa dos avós e ficou sabendo que esta se encontrava na casa da tia materna, casada com Bruno Pieleski, empregado na Usina Fiat-Lux, residente na Avenida Chicago, número 10.

O Desembargador procurou reaver a criança por conversa com os familiares, mas sem sucesso, “em prejuízo da menor, que não pôde receber do tio, nem do avô, a mesma educação e outros benefícios que lhe oferece o suplicante para a mesma”, para tanto, afirma que "esses senhores são pessoas paupérrimas”, pelo local onde residem. Que o único objetivo dele é de “educar e beneficiar, por outros meios, a menina que por sua senhora, fora criada desde os primeiros meses de sua existência ${ }^{8 ”}$.

A família Escobar apegara-se afetivamente à órfã, pois, desde os tenros meses de vida, haviam cuidado dela, principalmente a esposa, que tomava cuidado quando a mãe fazia os afazeres domésticos. Dessa forma, com base na alegada incapacidade dos familiares de cuidarem de Eulina, o Desembargador pediu a tutela da menina.

Em 11 de outubro, redigiu um pedido para tutelar a menor Eulina Barcellos Pinheiro, filha da falecida Julieta, então com 6 anos de idade, e o apresentou, dois dias depois, ao Juizado de Órfãos da $3^{\text {a }}$ Vara. Para reforçar seu pedido, anexou uma foto da menina, quando

\footnotetext{
${ }^{7}$ RIO GRANDE DO SUL. Juízo Districtal da Vara de Orphãos de Porto Alegre. $3^{\mathrm{a}}$ Vara. Tutela. Proc. $n^{\circ} 780$ de 1924. [manuscrito]. Porto Alegre, 1924. Localização: APERS. f. 2v.

${ }^{8}$ RIO GRANDE DO SUL. Juízo Districtal da Vara de Orphãos de Porto Alegre. $3^{a}$ Vara. Tutela. Proc. $n^{\circ} 780$ de 1924. [manuscrito]. Porto Alegre, 1924. Localização: APERS. f. 3.
} 
esta ainda estava sob seus cuidados, em 1922, acompanhada do atestado de óbito da mãe, para confirmar suas afirmações.

O Desembargador mencionou, na petição, que ele e "sua senhora criaram" a pequena Eulina, desde o ano de 1918, quando a menina tinha apenas 2 meses de vida. Declarava que ela estivera "sempre aos cuidados do suplicante e de sua senhora"; mesmo quando adoentada gravemente por "typho", ele havia custeado o seu tratamento, feito pelos doutores Ignácio Capistrano Cardoso e Raul Moreira, o primeiro, homeopata ${ }^{10}$, com consultório na Rua dos Andradas, número 605, e o segundo, professor de Clínica Pediátrica da Faculdade de Medicina, com consultório na mesma Rua dos Andradas, no número 246, “[a] os quais pagou regular quantia de honorários”.

A menina havia sido batizada e, "por convite do suplicante ${ }^{11 ", ~ o s ~ p a d r i n h o s ~ e r a m ~ o ~}$ médico José Ferreira Escobar, sobrinho do Desembargador, e a senhorita Zélia Santos Benício, filha do ex-deputado federal João Benício da Silva.

O Juiz do caso foi o Doutor Amado da Fonseca Fagundes que, no dia 15 de outubro, pediu vista do Curador Geral de Órfãos, Doutor Waldemar de Vasconcellos. No mesmo dia, de forma rápida e direta, respondeu com as iniciais “F. $J^{12}$." (Faça Justiça), ou seja, que se atribuísse o cargo de tutor ao suplicante.

No dia seguinte, o processo voltou ao Juiz que, também imediatamente, determinou que fosse lavrado e assinado o Termo de Tutela e Compromisso a favor de Manoel Ferreira Escobar Júnior.

Diante da impossibilidade de reaver a menina com os tios, Manoel Escobar redigiu uma nova solicitação, que foi juntada ao processo no dia 20, pedindo que a menor, que estava na casa dos tios, lhe fosse entregue. No mesmo dia, foi lavrado o mandato de Apreensão da

\footnotetext{
${ }^{9}$ Doença infecciosa, muito comum no período, que preocupava o governo do Estado. Caracteriza-se por cefalalgia (dores de cabeça), prostração (cansaço), febre e dores generalizadas. Designa-se uma febre contínua, contagiosa e sistêmica, causada por bacilos transmitidos pelas mãos, alimentos, moscas e bebidas contaminadas. "Quando detectados casos da febre, devia-se isolar o doente, ficando em contato com ele apenas uma ou duas pessoas, que deveriam seguir rigorosamente as medidas 'profiláticas': a esterilização dos materiais e das roupas, o recolhimento de todos os dejetos do doente, combate às moscas, uso da vacinação e notificação à Diretoria de Higiene”. WEBER, Beatriz Teixeira. As artes de curar: medicina, religião, magia e positivismo na República Rio-Grandense - 1889-1928. Santa Maria/RS: Editora da UFSM; Bauru/SP: Edusc, 1999, p. 86.

${ }^{10}$ A Homeopatia é uma doutrina médica, criada por um médico alemão, Cristiano Hahnemann, que procurava o equilíbrio entre a "força vital e o organismo", com a ingesta de substâncias em doses ínfimas visando à cura do paciente como um todo. Essa doutrina chegou ao Brasil em 1840; de início, houve disputas entre os médicos alopatas e os homeopatas, contudo muitos médicos aderiram à Homeopatia como forma de cura e esta era buscada pela sociedade (WEBER, 1999).

${ }^{11}$ RIO GRANDE DO SUL. Juízo Districtal da Vara de Orphãos de Porto Alegre. $3^{\text {a }}$ Vara. Tutela. Proc. $n^{\circ} 780$ de 1924. [manuscrito]. Porto Alegre, 1924. Localização: APERS. f. 2.

${ }^{12}$ RIO GRANDE DO SUL. Juízo Districtal da Vara de Orphãos de Porto Alegre. $3^{\text {a }}$ Vara. Tutela. Proc. $n^{\circ} 780$ de 1924. [manuscrito]. Porto Alegre, 1924. Localização: APERS. f. 9v.
} 
menor Eulina, que foi realizado, no dia 22, pelo Oficial de Justiça Alcides Francisco da Rosa, o qual fez a entrega da criança no Juízo dos Órfãos ao tutor.

Dessa forma, em 22 de outubro de 1924 a menor Eulina Barcellos Pinheiro voltou ao lar da família Escobar.

Menos de 10 dias, a contar da abertura do processo, a criança já estava com a família Escobar. Mas o caso estava longe de ser encerrado.

Cinco dias após a apreensão da menina, o advogado Jayme da Costa Pereira, procurador de Leonardo Barcellos Pinheiro, avô de Eulina, apresentou um pedido de Termo de Agravo, em relação à tutela da menor Eulina concedida a Manoel Ferreira Escobar. Referiu

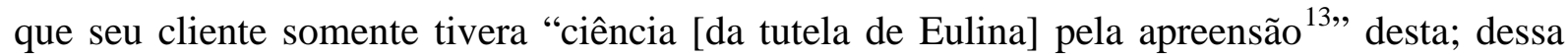
forma, o advogado Jayme Pereira recorreu ao Artigo 1.009 capítulo II, do Código Civil e Comercial do Estado (1908), referente aos Agravos. Reivindicou a admissão do Agravo baseado nos seguintes incisos do artigo:

$\S$ 26. Dos despachos que nomearem, destituírem ou não os tutores, curadores, inventariantes, testamenteiros, liquidantes de sociedades mercantis, síndicos de sociedade anônimas em liquidação forçada e quaisquer depositários judiciais; [...] § 42. Dos despachos proferidos contra literal disposição deste Código (p. 197-198).

No mesmo dia, o Juiz Amado da Fonseca Fagundes admite o Agravo “com

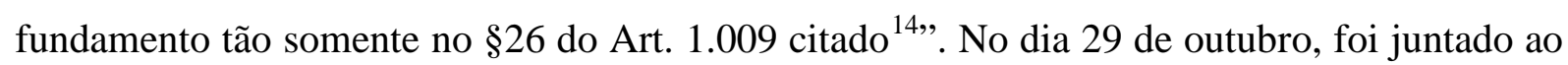
processo a Minuta de Agravo.

O procurador iniciava o Agravo questionando a decisão do Juiz ao referenciar que “o meritíssimo Juiz agravado, certamente olvidou ${ }^{15}$ da disposição clara do art. 409 e seus números, do Código Civil”. Segundo esse artigo, os familiares devem ser as primeiras pessoas a serem chamadas para assumir a responsabilidade legal sobre uma criança.

$\mathrm{O}$ avô da órfã afirmava que havia ficado sabendo que sua neta fora tutelada por Manoel Escobar Júnior somente quando esta fora apreendida, "pois não foi intimado para tomar parte no processo, que ocorreu a sua revelia”. Esclareceu que sua filha Julieta, mãe da menor Eulina, havia “deixado, durante algum tempo, a referida menor em companhia do Dr. Escobar, pois trabalhava em sua casa como doméstica”. Mas informava que, “depois de

\footnotetext{
${ }^{13}$ RIO GRANDE DO SUL. Juízo Districtal da Vara de Orphãos de Porto Alegre. $3^{\text {a }}$ Vara. Tutela. Proc. $n^{\circ} 780$ de 1924. [manuscrito]. Porto Alegre, 1924. Localização: APERS. f. 19.

${ }^{14}$ RIO GRANDE DO SUL. Juízo Districtal da Vara de Orphãos de Porto Alegre. $3^{\text {a }}$ Vara. Tutela. Proc. $n^{\circ} 780$ de 1924. [manuscrito]. Porto Alegre, 1924. Localização: APERS. f. 19v.

${ }^{15}$ Grifo nosso.
} 
algum tempo", Julieta voltara a morar com ele e havia trazido a menina "para viverem juntos”.

A mãe da criança falecera meses depois e ele, como avô, ficara com sua neta. Porém, como Julieta, “antes de falecer” pedira “à sua irmã, casada com Bruno Pieleski, que velasse pela menor, pois o casal não tinha filhos, como não tem até agora”, entregou Eulina para ser criada pela irmã e cunhado, esclarecendo o porquê de a menina "várias vezes [ter sido] encontrada em casa de sua tia materna ${ }^{16 ”}$. Para completar, afirma que a mãe da menina "nunca pretendeu fazer tutor da menor Eulina, o Dr. Escobar, e tanto que foi buscar a referida criança de sua companhia, trazendo para a casa do agravante ${ }^{17,}$.

O senhor Leonardo Barcellos Pinheiro, avô da menor, apesar do que alegava a outra parte, não era alguém desprovido de trabalho e recursos. Ele era funcionário público, por isso possuía uma renda regular. Mas, mesmo que isso não fosse mencionado no processo, somente o fato de seu procurador ter datilografado a Minuta de Agravo, já evidenciaria que ele possuía recursos para custear os serviços de um advogado, e um advogado caro, por sinal, pois a grande maioria dos processos, do Juízo dos Órfãos de Porto Alegre, no período, era redigido à caneta, uma vez que não era habitual, nem à Justiça nem aos advogados, disporem de máquinas de escrever.

O Agravo é terminado com as seguintes afirmações:

O agravante, como funcionário público que é, não tem em conta de rico, porém não pode ser classificado como indigente e, mais, julga ter o necessário para manter e educar sua neta, de acordo com sua posição social. Não são, somente, os ricos aqueles que sabem e podem dar educação aos seus filhos ou tutelados (Grifo nosso) ${ }^{18}$.

Dessa forma, o advogado termina o Agravo relativizando o posicionamento de que somente aquelas pessoas que possuíam mais recursos poderiam oferecer o melhor a uma criança. O avô poderia, como funcionário público, criar sua neta, talvez sem todas as "benesses” que um Desembargador poderia ofertar, mas, como este afirmava, “de acordo com sua posição”, levando a questionar a postura de que somente aqueles que têm recursos ou posição social distinta é que teriam o privilégio de criar uma criança.

\footnotetext{
${ }^{16} \mathrm{O}$ processo não apresenta o nome da tia materna, somente que esta é casada com Bruno Pieleski.

${ }^{17}$ RIO GRANDE DO SUL. Juízo Districtal da Vara de Orphãos de Porto Alegre. $3^{\text {a }}$ Vara. Tutela. Proc. $n^{\circ} 780$ de 1924. [manuscrito]. Porto Alegre, 1924. Localização: APERS. f. 21.

${ }^{18}$ RIO GRANDE DO SUL. Juízo Districtal da Vara de Orphãos de Porto Alegre. $3^{\text {a }}$ Vara. Tutela. Proc. $n^{\circ} 780$ de 1924. [manuscrito]. Porto Alegre, 1924. Localização: APERS. f. 21; 21v.
} 
No dia 30 de outubro, o Juiz Amado da Fonseca Fagundes pediu que os autos fossem baixados ao Cartório para que a eles fossem juntados um requerimento e documentos, que foram, naquele dia, entregues pelo Desembargador Manoel Ferreira Escobar Júnior. O documento intitulado "Histórico da menor Eulina ${ }^{19}$ " trata da história de Julieta Pinheiro, Eulina e dos cuidados que a família Escobar deu a elas.

Neste "Histórico", Manoel Escobar informa todo o cuidado e afeto dispensados com a menina, dessa forma, o Desembargador e sua esposa foram "dedicando-lhe a afeição fraternal, como se filha fosse, empregando minha senhora todos esses cuidados... no bem estar da

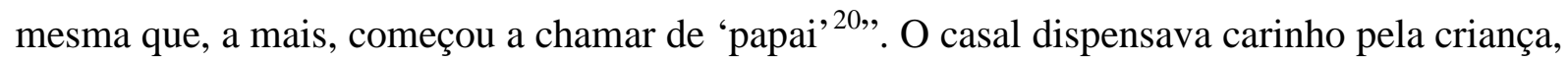
já que não possuíam filhos. Quando ficou sabendo da morte de Julieta Pinheiro, tentou, por várias vezes, conseguir, mediante conversa com os familiares, que estes lhe "entregassem a criança para educá-la e fazer-lhe outros benefícios de que seus parentes não podiam dispor, não ficando ela privada de os verem em qualquer tempo, tudo de balde”. Não obteve resposta afirmativa; porém, ao saber que Eulina se achava na casa dos tios, foi à Avenida Chicago e lá encontrou a "pobrezinha ${ }^{21 »}$ indo a uma venda próxima comprar pão ${ }^{22}$. Dessa forma, sem sucesso nas conversas, foi ao Juizado de Órfãos e requereu sua tutela.

A tutela da menina foi dada ao Desembargador, que solicitou a sua Apreensão. O Oficial de Justiça encontrou-a na casa dos tios; a entrega de Eulina não foi feita diretamente ao senhor Manoel Escobar, mas em audiência, no Juízo dos Órfãos, pelo Oficial de Justiça, que reportou que os tios acusaram a família Escobar de maus-tratos para com a criança. Na versão do senhor Escobar, a criança estava vestida com "farrapos que, talvez os filhos dos mendigos não usem. Com certeza, os tios supunham que, com as insinuações caluniosas, ela voltaria a casa deles, pois, do contrário, teriam pedido um prazo maior para entrega enquanto

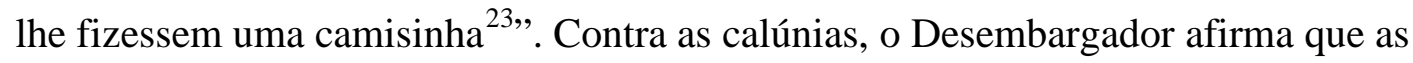

\footnotetext{
${ }^{19}$ RIO GRANDE DO SUL. Juízo Districtal da Vara de Orphãos de Porto Alegre. $3^{a}$ Vara. Tutela. Proc. $n^{\circ} 780$ de 1924. [manuscrito]. Porto Alegre, 1924. Localização: APERS. f. 24.

${ }^{20}$ RIO GRANDE DO SUL. Juízo Districtal da Vara de Orphãos de Porto Alegre. $3^{a}$ Vara. Tutela. Proc. $n^{\circ} 780$ de 1924. [manuscrito]. Porto Alegre, 1924. Localização: APERS. f. 24.

${ }^{21}$ RIO GRANDE DO SUL. Juízo Districtal da Vara de Orphãos de Porto Alegre. $3^{a}$ Vara. Tutela. Proc. $n^{\circ} 780$ de 1924. [manuscrito]. Porto Alegre, 1924. Localização: APERS. f. 25v.

${ }^{22}$ Segundo a moralidade em voga, no período, não era aconselhado que uma família permitisse que um menor, em especial do sexo feminino, andasse desacompanhado de um adulto pelas ruas e locais públicos (ESTEVES, 1989; VARGAS, 2004). Nesse caso, o Desembargador se apoia na moralidade para apontar o risco que a menor, de apenas 6 anos de idade, corria ao estar indo comprar pão, sozinha, com o consentimento de seus familiares, demonstrando, assim, a inaptidão desses responsáveis em zelar pelo cuidado de Eulina.

${ }^{23}$ RIO GRANDE DO SUL. Juízo Districtal da Vara de Orphãos de Porto Alegre. $3^{a}$ Vara. Tutela. Proc. $n^{o} 780$ de 1924. [manuscrito]. Porto Alegre, 1924. Localização: APERS. f. 26v.
} 
acusações, porém, que, por si próprias, destroem, desfazem-se como bolas de sabão no ar; porque, nem eu, nem minha senhora temos infligido maus-tratos às crianças em nossa companhia. Temos, pelo contrário, sido carinhosos e beneficentes para as mesmas como os podem dizer as pessoas que nos conhecem ${ }^{24}$.

Relembra que ele e sua senhora já haviam cuidado de duas meninas, que já estavam casadas, reafirmando as capacidades de bom encaminhamento que a família Escobar dava para aquelas de quem havia cuidado.

Como jurista experiente e de influência, menciona que quem irá “decidir de sorte dessa pobrezinha [é] um magistrado que me conhece há longos anos ${ }^{25}$, o Sr. Dr. João Baptista Gonçalves, ilustrado Juiz de Comarca”, o qual realizou o casamento das duas meninas "em nossa casa ${ }^{26 ”, ~ s e n d o ~ q u e ~ d e ~ u m a ~ d e l a s ~ f o i, ~ " p o r ~ i n i c i a t i v a ~ d o ~ D e s e m b a r g a d o r ~ A n d r e ́ ~ d a ~}$

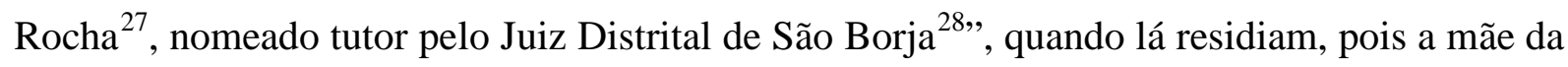
órfã casou-se em segundas núpcias, fato que segundo as Ordenações Filipinas, com a já referida condição de "honestidade” ou de recasamento da mãe ou da avó (Ord. Fil. liv. 4º tit. 102 §), perderia o pátrio poder.

Assim, o Desembargador aposentado recorre, como desfecho final, ao seu capital social para comprovar sua índole e capacidade de criação de uma criança, que, para as meninas, era conduzi-las até um honroso casamento.

Aproveitando que o processo estava no Juizado de Órfãos, o Juiz Amado da Fonseca Fagundes teceu algumas considerações sobre sua decisão anterior. Pelo fato de este parecer ser elucidativo, o apresentaremos em sua íntegra:

Não fiz agravo ao agravante em o despacho agravado, e como as razões da minuta não me convencem do contrário, mantenho o despacho de nomeação de tutor à menor órfã Eulina. Esta, como se vê nos autos, foi para a casa do Desembargador Escobar Júnior com dois meses de idade e daí saiu com cinco anos, tendo sido cuidada, carinhosamente, pelo casal Escobar, que a assistiu em sua doença, dando-lhe médicos e remédios, tendo mandado batizá-la e lhe dado padrinhos duas pessoas distintas.

\footnotetext{
${ }^{24}$ RIO GRANDE DO SUL. Juízo Districtal da Vara de Orphãos de Porto Alegre. $3^{\text {a }}$ Vara. Tutela. Proc. $n^{o} 780$ de 1924. [manuscrito]. Porto Alegre, 1924. Localização: APERS. f. 25v.; 26.

${ }^{25}$ Grifo nosso.

${ }^{26}$ RIO GRANDE DO SUL. Juízo Districtal da Vara de Orphãos de Porto Alegre. $3^{\text {a }}$ Vara. Tutela. Proc. $n^{\circ} 780$ de 1924. [manuscrito]. Porto Alegre, 1924. Localização: APERS. f. 26.

${ }^{27}$ Manoel André da Rocha, natural de Natal (Rio Grande do Norte), foi Desembargador, presidente do Superior Tribunal do Estado, segundo diretor da Faculdade de Direito de Porto Alegre e primeiro Reitor da Universidade de Porto Alegre, futura Universidade do Rio Grande do Sul e, consequentemente, Universidade Federal do Rio Grande do Sul.

${ }^{28}$ RIO GRANDE DO SUL. Juízo Districtal da Vara de Orphãos de Porto Alegre. $3^{\text {a }}$ Vara. Tutela. Proc. $n^{\circ} 780$ de 1924. [manuscrito]. Porto Alegre, 1924. Localização: APERS. f. 26v.
} 
Morta a mãe da dita menor, seu avô, atual agravante, a deixou em casa da sua tia - a senhora de Bruno Piesleki - até o dia em que foi ela procurada para ser entregue ao tutor, como se vê da inicial da certidão do oficial de justiça a fls. 21 e 15 [sic], sem com mesma menor se preocupar. A menor, sendo ouvida pelo juiz, declarou, terminantemente, que não quer sair da casa do "Papai", que é como ela trata o atual tutor, porque na casa deste é bem tratada, senta-se a mesa com ele, não é mandada à venda, como quando estava na casa da tia, e o Papai já lhe mostrou o colégio para onde ela deve ir instruir-se, sendo que sua tia nada disso fez.

Ora, entre seu avô que não pode, como funcionário público, que é de, categoria inferior, prover folgadamente a subsistência da neta, educando-a e instruindo-a, tanto que a entregou a uma filha, e uma pessoa como o tutor nomeado, que não tem filhos e possui bens capazes de lhe garantirem à dita menor, não só os meios de subsistência, educação e instrução, como também um futuro, como se vê da inicial, fls. 3, é claro que deve ser preferido o último, tendo-se em vista o bem estar presente e futuro do tutelado. É verdade que o Código Civil manda chamar, em primeiro lugar, os parentes para o exercício do encargo porque aos parentes incumbe os deveres decorrentes dos laços de parentescos e dos vínculos de sangue; mas, se os parentes do menor, por mais capazes que sejam para assumir tais responsabilidades, não podem, por suas condições de fortuna, garantir o futuro do menor, e de uma outra pessoa, idônea por todos os títulos, o garante, o Juiz não pode vacilar e é obrigado, pelos deveres decorrentes da sua função, a não cortar o futuro da criança, impondo-lhe uma tutela de parente.

É o que penso; entretanto o meritíssimo Sr.Dr. Juiz de Comarca resolverá como for de direito confirmando o despacho agravado ou dando provimento ao recurso ora interposto.

Sejam os autos conclusos ao meritíssimo Sr. Dr. Juiz de Comarca no prazo legal (Grifos nosso) ${ }^{29}$.

Dessa forma, o Juiz Amado da Fonseca Fagundes expressa sua opinião sobre o caso, mantendo a decisão anterior sobre o destino da menina Eulina. Além de justificar sua decisão anterior no parecer, algo não comum se apresentou em sua resolução. Quando a menina teria sido ouvida pelo Juiz? Tal questionamento se faz necessário uma vez que o processo, em nenhuma parte, faz referência à sua fala; o único momento em que a voz dela é descrita, por terceiro, foi no "Histórico” que o próprio Desembargador Manoel Escobar havia redigido, no qual, segundo ele, que ela o chamava de “Papai”. É possível que, ao ser entregue ao seu tutor pelo Oficial de Justiça, no Juizado de Órfãos, o Juiz tenha trocado com ela algumas palavras informais. Cremos que, mesmo assim, não haveria tempo para o tutor ter lhe mostrado o colégio onde iria estudar, a não ser que o próprio Juiz tenha recebido essas informações ao frequentar a casa da família Escobar, de maneira informal e amistosa.

Para além dessas conjecturas, o processo chegou às mãos de quem iria decidir sobre o caso no dia 05 de novembro de 1924. O Juiz de Comarca João Baptista Gonçalves foi mais

\footnotetext{
${ }^{29}$ RIO GRANDE DO SUL. Juízo Districtal da Vara de Orphãos de Porto Alegre. $3^{\text {a }}$ Vara. Tutela. Proc. $n^{\circ} 780$ de 1924. [manuscrito]. Porto Alegre, 1924. Localização: APERS. f. 35; 35v.; 36.
} 
econômico nas palavras do que o Juiz Distrital, porém bem mais direto ao mencionar que "não tomo conhecimento do agravo interposto a fls. porque no caso sujeito não se trata mais de uma nomeação de tutor e sim de um tutor nomeado e já compromissado, o qual, só poderá

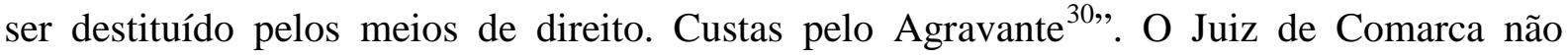
acolheu a ação movida pelo avô da criança, Leonardo Pinheiro, pelo fato de o motivo alegado no Agravo ser o questionamento da nomeação do tutor. O Juiz interpretou, de forma conveniente aos interesses de seu amigo Desembargador, que a ação deveria versar sobre a remoção de uma tutela, a qual deveria apresentar motivos de caráter social e econômico que impossibilitariam o tutor Manoel Escobar de exercê-la, ou mesmo motivos que colocariam em risco a menor se esta permanecesse sob a guarda de seu tutor. Assim, o Juiz de Comarca ratifica a permanência da menor Eulina com a família Escobar.

No dia 11 de novembro, todos os envolvidos no processo o assinam, confirmando que estão cientes da decisão do Juiz da Comarca e, depois dessa data, a família de Eulina paga as custas e não recorre mais da decisão de manter como tutor o Desembargador Manoel Ferreira Escobar Júnior. Após 3 anos, em 1927, o tutor de Eulina apresenta, de forma voluntária, os comprovantes dos gastos com escola, médico, dentistas. Também apresenta o boletim escolar da menina nos dois primeiros anos, evidenciando o progresso escolar da criança, que, em um ano, dentro de um escore de 1 até 5 , salta de 3, regular, para 4, boa, na avaliação, mantendo sua “conduta” com nota máxima nesses dois anos. O Juizado de Órfãos julgou todas as contas e ações corretas.

Dessa forma, o processo da menor Eulina foi encerrado.

\section{Tutelar ou adotar?}

Como este, outros processos de tutela foram abertos no município de Porto Alegre, entre 1900 a 1927, com a finalidade de cuidar e educar uma criança. Neste período, foram iniciados 823 autos de tutela, correspondendo a 1.290 menores tutelados, por 857 adultos, sendo a maioria dos tutores do sexo masculino (83\%) (CARDOZO, 2011).

A função de tutor pode ser considerada social, pois ela era dada a pessoas adultas para cuidarem de uma criança ou adolescente, pobre, rico ou mesmo exposto ${ }^{31}$ que, pelas vicissitudes da vida, não poderia mais continuar com seus progenitores (Ord. Fil. Liv. $1^{\circ}$, tit.

\footnotetext{
${ }^{30}$ RIO GRANDE DO SUL. Juízo Districtal da Vara de Orphãos de Porto Alegre. $3^{a}$ Vara. Tutela. Proc. $n^{\circ} 780$ de 1924. [manuscrito]. Porto Alegre, 1924. Localização: APERS. f. 38.

31 Os expostos, diferentemente dos outros órfãos, poderiam alcançar a maioridade aos 20 anos e, assim, emancipar-se.
} 
88). A nomeação desse adulto era feita no Juizado de Órfãos em até 30 dias, a contar do dia em que o menor havia ficado órfão (Ord. Fil. Liv. 4º tit. 102 §7).

A tutela poderia ser dada, até mesmo, se os pais do menor estivessem vivos, no caso de estes serem reconhecidos como incapazes ou proibidos de administrar os bens do menor (Ord. Fil. Liv. 1º tit. 88 §6), sendo necessária a nomeação de uma pessoa idônea para zelar pela criança ou adolescente.

O tutor tinha para com o menor e o Juízo dos Órfãos, segundo o Novo Roteiro dos Orphãos de 1903, os seguintes deveres:

a) Educar os órfãos, e fazê-los assoldadar quando for o caso.

b) Administrar-lhes os bens, como o faria um bom e prudente pai de família.

c) Dar conta exata dos respectivos rendimentos.

d) Dar-lhe indenização dos anos e prejuízos, que por sua culpa lhes provierem.

e) Autorizá-los e representá-los em tudo o que for de interesse deles (p. 26-27).

Dessa forma, segundo esse direcionamento baseado nas Ordenações Filipinas, havia uma série de compromissos que o tutor deveria se responsabilizar em assumir, bem como deveres que ajudavam a salvaguardar os bens, caso algum menor os possuísse, do interesse de uso de seu tutor em proveito próprio.

O cargo de tutor, por sua grande responsabilidade, tanto pelo cuidado para com a criança ou adolescente quanto pela questão pecuniária, poderia causar grandes danos a ele em virtude da não apresentação de algum comprovante de despesa. Caso houvesse alguma improbidade financeira verificada pelo Juiz de Órfãos, o tutor poderia até ser preso ${ }^{32}$.

Assim, como a história do processo de tutela da pequena Eulina, uma inquietação ficou em aberto ao se analisar os 823 processos de tutela do município de Porto Alegre no período de 1900 a $1927^{33}$. Se havia grande responsabilidade jurídica sobre os adultos que tutelavam os menores e se a argumentação daqueles que requeriam a tutela de um menor era

\footnotetext{
${ }^{32}$ Essa prestação de contas, na verdade, era mais requisitada para aquelas crianças que possuíssem algum pecúlio ou patrimônio, pois os tutores eram obrigados a realizar depósito de hipoteca legal, quando o menor possuísse bens, como forma de garantir que, se algo fosse apropriado indevidamente, dos bens do menor, estes seriam devolvidos, em Juízo, por meio da hipoteca legal do tutor.

${ }^{33}$ Em nossa dissertação de mestrado sobre o Juízo dos Órfãos em Porto Alegre nos anos iniciais do século XX, analisamos todos os processos de tutela disponíveis no Arquivo Público do Estado do Rio Grande do Sul APERS, instituição de resguarde da documentação. Nos processos judiciais a empatia e a afetividade eram argumentos recorrentemente utilizados para legitimar ou remover a guarda de uma criança ou adolescente (CARDOZO, 2011).
} 
que desejavam cuidar deste, a questão que se impõe é: Por que escolher tutelar ao invés de adotar uma criança ou adolescente?

Em muitos casos, percebemos que havia totais indícios de intenções benéficas dos adultos para com os menores; como no caso acima em que a palavra "papai” foi atribuída à menina em relação ao seu tutor. Dessa forma, se em alguns casos havia tanto afeto entre tutores e tutelados, por que os adultos não escolhiam adotar o menor?

Acompanhado o processo da menina Jandyra $^{34}$, de oito anos de idade, podemos verificar que havia alternativas no período para proteger os menores, que não só a tutela.

O senhor Mazarino Moraes, no dia 21 de dezembro de 1911, informou ao Juízo dos Órfãos que

há sete anos o supl. tomou a si a criação e educação da menor Jandyra, filha natural de Amália Antonia, já falecida, sendo que naquela época dita menor tinha apenas um ano de idade;

que no dia 21 de agosto do corrente ano [1911] faleceu nesta cidade a esposa do supl., obrigando a recolher ao 'Colégio Rio Branco', por sua conta, como interna a referida menor;

que em face do exposto e atendendo a circunstâncias de ter o supl. de ausentar-se temporariamente desta capital, torna-se necessária a nomeação de um tutor provisório à referida menor. Cumpre que fique consignado [sic] que todas as despesas com a aludida menor correrão por conta do supl. ${ }^{35}$

No dia seguinte, o Juiz Hugo Teixeira nomeou o senhor Octaviano Manoel de Oliveira, mas o processo não indica se a menina ou Mazarino Morais possuíam qualquer tipo de relação com o tutor nomeado. O Termo de Tutela e Compromisso foi assinado em 29 de dezembro de 1911.

Até aquele dia, o processo correra como os outros, sem maiores novidades, porém a situação mudou em 04 de janeiro de 1912, quando foi anexado o seguinte pedido de Mazarino de Morais:

O infraescrito, tendo, de acordo com as escrituras públicas juntas, adotado como sua filha a menor impúbere Jandyra, cuja filiação consta na certidão do registro de seu nascimento, também junta, vem para o efeito de serem ultimadas todas as formalidades legais exigíveis, completando-se 3 que já das aludidas escrituras consta,

\footnotetext{
${ }^{34}$ RIO GRANDE DO SUL. Juízo Districtal da Vara de Orphãos de Porto Alegre. $3^{\text {a }}$ Vara. Tutela. Proc. $n^{\circ} 587$ de 1911. [manuscrito]. Porto Alegre, 1911. Localização: APERS.

${ }^{35}$ RIO GRANDE DO SUL. Juízo Districtal da Vara de Orphãos de Porto Alegre. $3^{\text {a }}$ Vara. Tutela. Proc. $n^{\circ} 587$ de 1911. [manuscrito]. Porto Alegre, 1911. Localização: APERS. f. 2.
} 
pedir que lhe seja mandado passar a competente carta de adoção, depois de ser esta, bem como os documentos que a acompanham, juntos ou apensados aos autos de nomeação de tutela, em que são partes como tutor Octaviano Manoel de Oliveira e tutelada a menor Jandyra de quem nesta se trata (Grifo nosso) ${ }^{36}$.

Nesse pedido, verifica-se algo ausente no restante dos casos analisados; dos 823 processos estudados somente em um foi apresentado o pedido para se adotar uma criança ou adolescente! No dia 10 de janeiro de 1912, depois de ouvir o Curador Geral, que escrevera “nada a requerer ${ }^{37 ”, ~ o ~ J u i z ~ H u g o ~ T e i x e i r a ~ s o l i c i t o u ~ a ~ a v a l i a c ̧ a ̃ o ~ d o ~ J u i z ~ d e ~ C o m a r c a . ~ D o i s ~ d i a s ~}$ após, o Juiz de Comarca Manoel Ferreira de Escobar Junior (o Desembargador aposentado do processo anterior) pediu que o "peticionário” provasse sua cidade de nascimento e idade, pois essas informações não constavam nos autos, para assim este poder deferir o pedido de adoção

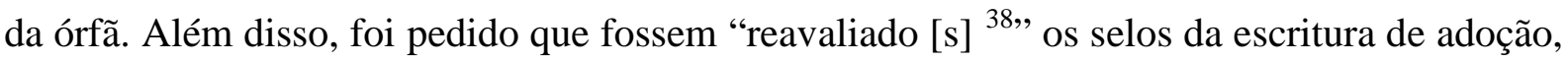
ou seja, que fosse confirmada a autenticidade do documento.

Mazarino Morais, no dia 5 de fevereiro, informara que tinha 44 anos de idade e que havia nascido "na cidade de Santa Maria da Boca do Monte a quatorze de agosto do ano de $1917^{39}$ ”. Os autos sobiram, novamente, ao Juiz de Comarca que, em 20 de fevereiro, apontou: “confirmo a adoção ${ }^{40 ”}$. Após esse dia, Jandyra tornou-se a filha de Mazarino Morais.

Há outros casos de adoção no município de Porto Alegre, como o da pequena Aramita ${ }^{41}$, de nove anos de idade que, no $1^{\circ}$ Tabelionato de Porto Alegre, foi adotada pelo senhor Arlindo Brasil e sua esposa Maria Emilia Brasil. Eles, no dia 27 de agosto de 1901, “de sua livre e espontânea vontade”, "reconheceram por sua filha adotiva a menor Aramita”, pois "não tendo eles herdeiros necessários, ascendentes ou descendentes, adotaram e perfilharam a referida Aramita para todos os efeitos jurídicos e particularmente para sucederlhes em seus bens, direitos e ações como se filha legítima fosse [...]” 42 .

\footnotetext{
${ }^{36}$ RIO GRANDE DO SUL. Juízo Districtal da Vara de Orphãos de Porto Alegre. $3^{\text {a }}$ Vara. Tutela. Proc. $n^{\circ} 587$ de 1911. [manuscrito]. Porto Alegre, 1911. Localização: APERS. f. 4.

${ }^{37}$ RIO GRANDE DO SUL. Juízo Districtal da Vara de Orphãos de Porto Alegre. $3^{a}$ Vara. Tutela. Proc. $n^{\circ} 587$ de 1911. [manuscrito]. Porto Alegre, 1911. Localização: APERS. f. 10v.

${ }^{38}$ RIO GRANDE DO SUL. Juízo Districtal da Vara de Orphãos de Porto Alegre. $3^{\text {a }}$ Vara. Tutela. Proc. $n^{\circ} 587$ de 1911. [manuscrito]. Porto Alegre, 1911. Localização: APERS. f. 11.

${ }^{39}$ RIO GRANDE DO SUL. Juízo Districtal da Vara de Orphãos de Porto Alegre. $3^{a}$ Vara. Tutela. Proc. $n^{\circ} 587$ de 1911. [manuscrito]. Porto Alegre, 1911. Localização: APERS. f. 15.

${ }^{40}$ RIO GRANDE DO SUL. Juízo Districtal da Vara de Orphãos de Porto Alegre. $3^{a}$ Vara. Tutela. Proc. $n^{\circ} 587$ de 1911. [manuscrito]. Porto Alegre, 1911. Localização: APERS. f. 16v.

${ }^{41}$ RIO GRANDE DO SUL. $1^{\circ}$ Tabelionato de Porto Alegre. Livro de Contractos n 22. Escriptura de Adopção. [manuscrito]. Porto Alegre, 1901. Localização: APERS.

${ }^{42}$ RIO GRANDE DO SUL. $1^{\circ}$ Tabelionato de Porto Alegre. Livro de Contractos no 22. Escriptura de Adopção. [manuscrito]. Porto Alegre, 1901. Localização: APERS. f. 25. (Grifos nosso).
} 


\section{Considerações finais}

O motivo que levava os adultos a optarem pela tutela, em vez da adoção, talvez residisse nos custos que esse tipo de ação poderia acarretar, mas verificando os processos de tutela do mesmo período, percebemos que esses eram de custos mais elevados dos que os de adoção. Nos autos de tutela, só na petição inicial, eram cobrados, em média, 400 réis, fora os outros gastos até o final do processo; já a escritura de adoção tinha valor fixado em 300 réis.

Podemos imaginar, então, por meio dessa escritura de adoção, que os adultos que tutelavam menores optavam pela tutela ao invés da adoção, por conta, talvez, da partilha dos bens, pois esses menores adotados teriam todos os direitos legais de um filho biológico ${ }^{43}$.

Além disso, acreditamos que, ao escolher a tutela, poderiam ser evitados julgamentos e que seriam concedidos maiores benefícios para os adultos do que, propriamente, para as crianças ou adolescentes, pois vale recordar que o tutor poderia "se desfazer" da guarda do menor no momento que achasse mais oportuno e por motivos variados, como ter que se retirar da cidade, referido no caso da menor Jandyra, ou mesmo, evitar que o patrimônio familiar fosse dilapidado.

Não podemos esquecer que a adoção, no Brasil, somente com o Código Civil de 1916 (1917), que foi promulgado no ano seguinte, viria a se tornar um processo judicial. Antes desse marco regulatório a adoção era realizada em tabelionatos de forma rápida e sumária ${ }^{44}$.

Também não podemos olvidar que a adoção poderia ser revogada, por desrespeito do adotado ou de comum acordo entre as partes, mas mesmo com essa possibilidade de separação, a adoção trazia maior proteção aos menores, dando-lhes um nome e um sobrenome e, quem sabe, um patrimônio que poderia garantir-lhes um futuro melhor ${ }^{45}$. E isso transparece

\footnotetext{
${ }^{43}$ Diferentemente daqueles filhos reconhecidos em testamento, essas crianças adotadas, muito antes da hora da morte de um adulto, se tornavam membros dessa família e assim herdeiros de um nome e de bens.

${ }^{44}$ Mesmo no período monárquico podemos verificar a prática da adoção conforme Alessandra Moreno (2007) que investigou a adoção na cidade de São Paulo entre os anos de 1765 e 1822, contrariando uma produção historiográfica que negava a existência da adoção formal antes do século XX, tendo como razão a ausência de leis portuguesas que regulamentassem o tema. Essa autora verificou, por meio de cartas e processos de adoção, baseados nos princípios do Direito Romano, que os pretendentes à adoção reclamavam o acolhimento de crianças órfãs, enjeitadas, filhas de parentes próximos. Apesar dos preconceitos da época, como o da incapacidade de ter sua própria prole, a adoção foi uma das formas sociofamiliares de incorporação de menores advindos de lares alheios. Dentre os autores que escreveram só haver adoções informais nas sociedades portuguesa e brasileira antes do século XX, podemos citar Isabel Sá (1995) e Maria Luiza Marcílio (2006).

${ }^{45}$ O Código Civil (1917) estabelecia que somente as pessoas sem filhos legítimos teriam o direito a adotar, a idade mínima para do adotante seria de 50 anos e não haveria limite para a idade do adotado, porém deveria se ter, pelo menos, 18 anos de diferença entre elas. A adoção tinha caráter revogável. A filiação do adotado era considerada aditiva, ou seja, parentesco civil entre o adotante e o adotado, sem romper por completo o vínculo biológico. Caso houvesse filhos legítimos depois da realização da adoção, o adotado teria direito a metade do que cabia ao legítimo.
} 
no levantamento das Escrituras de Adoção do município de Porto Alegre, nos anos de 1900 a 1917, pois havia adoções de crianças de 1 mês de vida, como da pequena Thereza ${ }^{46}$, e até de adultos com 29 anos de idade, como o caso de Adolfo João Heinrichs ${ }^{47}$, que podem apontar para a continuidade de uma família, por meio da perpetuação do sobrenome, a preservação dos bens dessa ou mesmo o cuidado que o filho teria para com seus pais adotivos na velhice. As escrituras de adoção, que não são processos judiciais como atualmente, revelam que, apesar de terem sido acionados quase 10 vezes menos que os processos de tutela, eram uma alternativa para a população porto-alegrense cuidar de uma criança ou adolescente que pelas atribulações da vida não poderia mais continuar com seus pais biológicos.

\title{
"BEST FOR WHOM?" - The Orphan Court and the discourse of valuing and protecting minors in the early twentieth century
}

\begin{abstract}
In the early twentieth century, the ongoing social discourse was about valuing and protecting minors. In this period, a number of adults requested to be granted the guardianship of children in order to watch over their health, diet, housing and education. Guardianship was a commitment requested by a person to the Orphan Court to manage the assets and physical integrity of the minor. However, if the discourse was to take care of the minor's well-being, why did adults opt for guardianship instead of adoption? This study addresses the issue and proposes some answers for this question.
\end{abstract}

Keywords: Guardianship. Adoption. Minors.

\section{Referências}

ALANIZ, Anna Gicelle García. Ingênuos e libertos: estratégias de sobrevivência familiar em épocas de transição (1871-1895). Campinas/SP: CMU/UNICAMP, 1997.

ALMEIDA, Cândido Mendes de. Código Filipino ou Ordenações e leis do Reino de Portugal, recompiladas por mandado do rei D. Philippe I. 14. ed. Rio de Janeiro: Tipografia do Instituto Philomathico, 1870. Disponível em: <http://www1.ci.uc.pt/ihti/proj/ filipinas/>. Acesso em: 11 mar. 2011.

\footnotetext{
${ }^{46}$ RIO GRANDE DO SUL. $1^{\circ}$ Tabelionato de Porto Alegre. Livro de Contractos no 22. Escriptura de Adopção. [manuscrito]. Porto Alegre, 1901. Localização: APERS. f. 41.

${ }^{47}$ RIO GRANDE DO SUL. $1^{\circ}$ Tabelionato de Porto Alegre. Livro de Contractos n ${ }^{\circ} 31$. Escriptura de Adopção. [manuscrito]. Porto Alegre, 1910. Localização: APERS. f. 62v; 63.
} 
ALVES, João Luiz. Código Civil: da República dos Estados Unidos do Brasil: promulgado pela Lei n. 3071, de 1 de janeiro de 1916. Rio de Janeiro: F. Briguiet, 1917. Localização: Biblioteca da Faculdade de Direito da UFRGS (BIBDIR-UFRGS).

AZEVEDO, Gislane Campos. De Sebastianas e Geovannis: o universo do menor nos processos dos juízes de órfãos da cidade de São Paulo (1871-1917). Dissertação (Mestrado em História), Pontifícia Universidade Católica de São Paulo, São Paulo, 1995.

CARDOZO, José Carlos da Silva. Enredos tutelares: o Juizado de Órfãos e a (re) organização da família porto-alegrense no início do século XX. Dissertação (Mestrado em História), Universidade do Vale do Rio dos Sinos, São Leopoldo, RS, 2011.

ESTEVES, Martha Abreu. Meninas perdidas: os populares e o cotidiano do amor no Rio de Janeiro da Belle Époque. Rio de Janeiro: Paz e Terra, 1989.

FONSECA, Cláudia. Caminhos da adoção. 3. ed. São Paulo: Cortez, 2006.

LEWKOWICZ, Ida; et al. Trabalho compulsório e trabalho livre na história do Brasil. São Paulo: Editora UNESP, 2008.

MARCÍLIO, Maria Luiza. História social da criança abandonada. 2. ed. São Paulo: Hucitec, 2006.

MORENO, Alessandra Zorzetto. Vivendo em lares alheios: acolhimento domiciliar, criação e adoção na cidade de São Paulo (1765-1822). Tese (Doutorado em História). Universidade Estadual de Campinas, Campinas, SP, 2007.

NOVO roteiro dos orphãos: ou guia pratica do processo orphanológico no Brazil: fundamentado na legislação respectiva, e illustrado pela lição dos praxistas, contendo muitas disposições novas a aréstos dos tribunaes, até ao presente, com o formulário de todos os processos. 3. ed. Rio de Janeiro: Laemmert, 1903. Localização: BIBDIR-UFRGS.

PAPALI, Maria Aparecida C. R. Escravos, libertos e órfãos: a construção da liberdade em Taubaté (1871-1895). São Paulo: Annablume; FAPESP, 2003.

PINHEIRO, Luciana de Araújo. A civilização do Brasil através da infância: propostas e ações voltadas à criança pobre nos finais do Império (1879-1889). Dissertação (Mestrado em História). Universidade Federal Fluminense, Niterói, RJ, 2003.

RIO GRANDE DO SUL. $1^{\circ}$ Tabelionato de Porto Alegre. Livro de Contratos $\mathrm{n}^{\circ} 22$. Escriptura de Adopção. [manuscrito]. Porto Alegre, 1901. Localização: APERS.

RIO GRANDE DO SUL. Código do processo civil e commercial do estado do Rio Grande do Sul: Lei n. 65 de 16 de janeiro de 1908: (edição official). Porto Alegre: Officinas Typographicas d' "A Federação", 1908. Localização: BIBDIR-UFRGS.

RIO GRANDE DO SUL. $1^{\circ}$ Tabelionato de Porto Alegre. Livro de Contractos $\mathrm{n}^{\circ} 31$. Escriptura de Adopção. [manuscrito]. Porto Alegre, 1910. Localização: APERS. 
RIO GRANDE DO SUL. Juízo Districtal da Vara de Orphãos de Porto Alegre. $3^{\mathrm{a}}$ Vara. Tutela. Proc. $n^{\circ} 587$ de 1911. [manuscrito]. Porto Alegre, 1911. Localização: APERS.

RIO GRANDE DO SUL. Juízo Districtal da Vara de Orphãos de Porto Alegre. $3^{\text {a }}$ Vara. Tutela. Proc. $n^{\circ} 780$ de 1924. [manuscrito]. Porto Alegre, 1924. Localização: APERS.

RODRIGUEZ, Sônia Maria Troitiño. O Juízo de Órfãos de São Paulo: caracterização de tipos documentais (XVI-XX). Tese (Doutorado em História), Universidade de São Paulo, 2010.

SÁ, Isabel dos Guimarães. A circulação de crianças na Europa do Sul: o caso dos expostos do Porto no século XVIII. Lisboa: Fundação Calouste Gulbenkian; Junta Nacional de Investigação Científica e Tecnológica, 1995.

VARGAS, Anderson Zalewski. Porto Alegre, início do século XX: imprensa, "ânsia de civilização” e menores de rua. In: GRIJÓ, Luiz Alberto; et al. (Org.). Capítulos de história do Rio Grande do Sul. Porto Alegre: Editora da UFRGS, 2004. p. 247-272.

WEBER, Beatriz Teixeira. As artes de curar: medicina, religião, magia e positivismo na República Rio-Grandense - 1889-1928. Santa Maria/RS: Editora da UFSM; Bauru/SP: Edusc, 1999.

ZANELLA, Ana Paula. A administração do Juizado de Menores do Rio Grande do Sul nos seus primórdios (1933 a 1945). Revista Justiça \& História. Tribunal de Justiça do Estado do Rio Grande do Sul, Porto Alegre, v. 3, n. 5, p. 225-243, 2003.

ZERO, Arethuza Helena. O preço da liberdade: caminhos da infância tutelada - Rio Clara (1871-1888). Dissertação (Mestrado em História), Universidade Estadual de Campinas, Campinas, SP, 2004. 